\title{
Microsatellite typing and susceptibilities of serial Cryptococcus neoformans isolates from Cuban patients with recurrent cryptococcal meningitis
}

\author{
María T Illnait-Zaragozí ', Gerardo F Martínez-Machín', Carlos M Fernández-Andreu', Ferry Hagen², Teun Boekhout ${ }^{2}$,
} Corné HW Klaassen ${ }^{3}$, Jacques F Meis ${ }^{3^{*}}$

\begin{abstract}
Background: Cryptococcus neoformans is commonly associated with meningoencephalitis in immunocompromised patients and occasionally in apparently healthy individuals. Recurrence of infection after initial treatment is not uncommon. We studied C. neoformans isolates from 7 Cuban patients with recurrent cryptococcal meningitis. Antifungal susceptibility and genotyping with microsatellite molecular typing were carried out.

Methods: Isolates $(n=19)$ were recovered from cerebrospinal fluid, blood, urine and semen. Antifungal susceptibilities for amphotericin B, fluconazole, flucytosine, itraconazole, voriconazole, posaconazole and isavuconazole were tested by CLSI M27A3 broth microdilution method. Genotyping was done using a panel of 9 microsatellite (STR) markers: (CT)n, (TG)n, (TA)n, (CTA)n, (TCT)n, (CCA)n, (TTAT)n, (ATCC)n and (TATT)n.

Results: The average number of isolates/patient was 2.71. The mean time interval between the collection of any two isolates was 52.5 days. All strains were identified as C. neoformans var. grubii (serotype A $\alpha$ ). Although none of the strains were resistant to the studied drugs, in serial isolates from two patients, MICs values of triazoles increased 4-5 $\log _{2}$ dilutions over time. STR patterns showed 14 distinctive profiles. In three patients the recurrent infection was associated with genotypically identical isolates. The four other patients had relapse isolates which were genotypically different from the initial infecting strain.
\end{abstract}

Conclusion: Recurrences of cryptococcal meningitis in our series of patients was not associated with development of drug resistance of the original strain but by an initial infection with different strains or a reinfection with a new strain.

\section{Background}

The incidence of cryptococcosis started to increase with the beginning of the acquired immune deficiency syndrome (AIDS) epidemic in the early $1980 \mathrm{~s}$. Its frequency declined in the Western world since the mid 1990 s due to the use of highly active antiretroviral therapy (HAART). However, cryptococcal meningitis is still one of the most common life-threatening opportunistic fungal infections in immunocompromised patients, particularly among those with AIDS in Sub-Saharan Africa [1] and Asia [2]. These patients show a high tendency to

\footnotetext{
* Correspondence: j.meis@cwz.nl

${ }^{3}$ Department of Medical Microbiology and Infectious Diseases, Canisius

Wilhelmina Hospital, Nijmegen, The Netherlands

Full list of author information is available at the end of the article
}

relapse despite effective antifungal therapy. Early studies performed with karyotyping and restriction fragment length polymorphism (RFLP) analysis of serial isolates of AIDS patients in New York concluded that recurrent infection was caused through persistence of the original strain and not from infection with new strains [3,4]. A later study using the same typing technique but with isolates from AIDS patients from Uganda found that among 17 patients with more than 1 cerebrospinal fluid (CSF) isolate of Cryptococcus neoformans, sequential isolates were identical or highly related in 12 patients [5].

Several treatment strategies have been used in patients with cryptococcal meningitis but the optimum regimen is still not clear. Amphotericin B with or without flucytosine remain the agents of choice for induction therapy

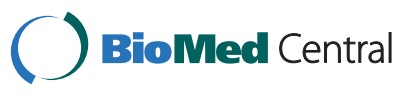

(c) 2010 IIInait-Zaragozí et al; licensee BioMed Central Ltd. This is an Open Access article distributed under the terms of the Creative Commons Attribution License (http://creativecommons.org/licenses/by/2.0), which permits unrestricted use, distribution, and reproduction in any medium, provided the original work is properly cited. 
while fluconazole has proven to be superior for longterm maintenance therapy [6,7]. High dose fluconazole with flucytosine is an oral treatment alternative although this regimen is not as effective as amphotericin B and flucytosine [8]. Different molecular typing methods have been used in the epidemiological analyses of clinical and/or environmental isolates of C. neoformans, including electrophoretic karyotyping, PCR fingerprinting, random amplified polymorphic DNA analysis, RFLP analysis, MLST and amplified fragment length polymorphism analysis with divergent results [9-11]. To determine whether recurrences of cryptococcal meningitis in seven Cuban patients were due to development of drug resistance or to infection by multiple strains, we tested the in vitro antifungal susceptibility and determined the genotypes of the sequential isolates using a recently described microsatellite based assay [12].

\section{Methods \\ Fungal isolates}

From the stock collection of the mycology laboratory at the Instituto de Medicina Tropical "Pedro Kourí" (IPK) in Havana, Cuba, 19 clinical isolates of C. neoformans from patients with recurrent infection were selected for this study. The isolates were recovered at different time intervals from cerebrospinal fluid $(\mathrm{n}=16)$, blood, urine and semen (one each) from 7 patients (6 HIV positive and 1 HIV negative) admitted at the institute between 1995 and 2001, just before HAART was introduced in Cuba (Table 1). All patients were admitted to the clinical AIDS care division at the IPK. Initial isolates were obtained at diagnosis and before any antifungal therapy was used and follow up isolates were from patients during or after treatment with antifungal drugs. Repeat lumbar puncture was only performed in those cases which did not react within two weeks of therapy or those who showed a clinical deteriorisation during or after treatment. From each culture positive sample a single isolate from morphological similar colonies was archived. Species identification was initially done by growth on canavanine-glycine-bromothymol blue (CGB) agar and strains were stored in sterile water at room temperature until the study was carried out. From initial isolation until the study the isolates were typically subcultured between 4 and 6 times. Before use, the identification of all isolates was repeated with a commercial identification system (Auxacolor 2; Bio-Rad, Marnes-laCoquette, France).

\section{Antifungal agents and susceptibility testing}

Broth microdilution testing was performed in accordance with Clinical and Laboratory Standards Institute document M27-A3 guidelines [13]. Standard antifungal powders of amphotericin B (Sigma, The Netherlands), flucytosine (Valeant Pharmaceuticals, The Netherlands), fluconazole (Pfizer Central Research, U.K.), itraconazole (Janssen-Cilag, The Netherlands), voriconazole (Pfizer Central Research, U.K.), posaconazole (Schering Plough, USA), and isavuconazole (Basilea Pharmaceutica, Switzerland) were used. The stock solutions of the drugs were prepared in the appropriate solvent. The final concentrations of the antifungal agents were 0.016 to $8 \mu \mathrm{g} /$ $\mathrm{mL}$ for amphotericin $\mathrm{B}$, itraconazole, voriconazole, and posaconazole; 0.063 to $32 \mu \mathrm{g} / \mathrm{mL}$ for flucytosine and fluconazole; and 0.004 to $4.00 \mu \mathrm{g} / \mathrm{mL}$ for isavuconazole. After $72 \mathrm{~h}$ incubation at $35^{\circ} \mathrm{C}$ the minimum inhibitory concentration (MIC) was defined as the lowest concentration of drug showing absence of growth for amphotericin B and a prominent reduction of growth $(250 \%)$ for the other antifungal agents compared to the drug-free growth control. The MICs were read optically and spectrophotometrically at $420 \mathrm{~nm}$ after agitation. Candida parapsilosis ATCC 22019 and C. krusei ATCC 6258 were used as quality control [13].

\section{Mating-, sero- and genotyping}

C. neoformans isolates were grown on Sabouraud's dextrose agar at $30^{\circ} \mathrm{C}$ for $48 \mathrm{~h}$ and DNA was obtained from freshly grown cells using a MagNA lyser/MagNA Pure protocol (Roche Diagnostics, Almere, the Netherlands). The mating- and serotype was determined using four different PCRs that specifically amplify the mating-type a or $\alpha$ allele of the STE2O locus for either serotype A or $\mathrm{D}$ isolates [14]. The reference isolates CBS9172 (aA), CBS8710 $(\alpha \mathrm{A}), \mathrm{CBS} 10511(\mathrm{aD})$ and CBS10513 $(\alpha \mathrm{D})$ were included as positive control for each of the four PCRs.

STR analysis was performed in two steps as described previously [12]: i) Amplification of STR loci by PCR: three separate multiplex PCRs were used (CNA2, CNA3, and CNA4, respectively), each amplifying three different STRs. For every multiplex PCR, one of the amplification primers was labelled with carboxyfluorescein (FAM), hexachlorofluorescein (HEX), or tetrachlorofluorescein (TET) at the 5 ' end, respectively. In addition to the amplification primers (concentrations according to reference [11]), each PCR mixture contained $0.2 \mathrm{mM}$ deoxynucleoside triphosphates, $1 \mathrm{U}$ of FastStart Taq DNA polymerase (Roche Diagnostics), 2 $\mathrm{mM} \mathrm{MgCl}{ }_{2}$ and $1 \mathrm{ng}$ of genomic DNA in $1 \times$ reaction buffer. Thermocycling was performed in a T1 thermocycler (Biometra, Göttingen, Germany) by using the following thermal protocol: $10 \mathrm{~min}$ of denaturation at $95^{\circ}$ C, followed by 35 cycles of $30 \mathrm{~s}$ of denaturation at $95^{\circ} \mathrm{C}$, $30 \mathrm{~s}$ of annealing at $60^{\circ} \mathrm{C}$, and $1 \mathrm{~min}$ of extension at $72^{\circ}$ C. Before the reaction mixtures were cooled to room temperature, an additional incubation for $10 \mathrm{~min}$ at $72^{\circ}$ $\mathrm{C}$ was performed. All temperature transitions were 
Table 1 Clinical data, origin and date of isolation of the studied strains

\begin{tabular}{|c|c|c|c|c|c|c|c|}
\hline $\begin{array}{l}\text { Patient } \\
\text { Nr. }\end{array}$ & Sex & $\begin{array}{c}\text { HIV/ } \\
\text { Year of diagnosis }\end{array}$ & Sample & $\begin{array}{l}\text { Isolation } \\
\text { date }\end{array}$ & $\begin{array}{c}\text { Interval between each } \\
\text { isolate in days } \\
\text { (number) }\end{array}$ & Total of days & $\begin{array}{l}\text { Antifungal } \\
\text { treatment }\end{array}$ \\
\hline \multirow[t]{3}{*}{1} & Male & $+/ 1991$ & Blood & 14/04/95 & $\begin{array}{c}0 \\
(08-36-09-92)\end{array}$ & 0 & $\begin{array}{c}\text { AmB+Flu } \\
\text { Flu (maintenance) }\end{array}$ \\
\hline & & & CSF & $14 / 04 / 95$ & $\begin{array}{c}0 \\
(08-36-09-75) \\
\end{array}$ & 0 & $\begin{array}{c}\text { AmB+Flu } \\
\text { Flu (maintenance) }\end{array}$ \\
\hline & & & CSF & 18/07/95 & $\begin{array}{c}96 \\
(08-36-10-01) \\
\end{array}$ & 96 & $\mathrm{AmB}+\mathrm{Flu}$ \\
\hline \multirow[t]{3}{*}{2} & Male & $+/ 1990$ & CSF & 05/09/95 & $\begin{array}{c}0 \\
(08-36-09-97) \\
\end{array}$ & 0 & Flu+ltr \\
\hline & & & Urine & $08 / 12 / 95$ & $\begin{array}{c}95 \\
(08-36-09-70) \\
\end{array}$ & 95 & Flu \\
\hline & & & CSF & 10/01/96 & $\begin{array}{c}34 \\
(08-36-09-91)\end{array}$ & 129 & Flu \\
\hline \multirow[t]{2}{*}{3} & Female & $+/ 1994$ & CSF & 18/01/96 & $\begin{array}{c}0 \\
(08-36-09-71) \\
\end{array}$ & 0 & $\begin{array}{c}\text { AmB+Flu } \\
\text { Flu (maintenance) }\end{array}$ \\
\hline & & & CSF & 29/02/96 & $\begin{array}{c}34 \\
(08-36-09-72) \\
\end{array}$ & 34 & $\mathrm{AmB}+\mathrm{Flu}$ \\
\hline \multirow[t]{2}{*}{4} & Male & $+/ 1995$ & CSF & 23/04/97 & $\begin{array}{c}0 \\
(08-36-09-82) \\
\end{array}$ & 0 & $\mathrm{AmB}+\mathrm{FC}+\mathrm{Flu}$ \\
\hline & & & CSF & $06 / 05 / 97$ & $\begin{array}{c}14 \\
(08-36-09-89)\end{array}$ & 14 & $\mathrm{AmB}+\mathrm{FC}+\mathrm{Flu}$ \\
\hline \multirow[t]{2}{*}{5} & Male & $+/ 1998$ & CSF & $15 / 04 / 00$ & $\begin{array}{c}0 \\
(08-36-09-24) \\
\end{array}$ & 0 & $\begin{array}{c}\text { AmB } \\
\text { Flu (maintenance) }\end{array}$ \\
\hline & & & CSF & 26/10/00 & $\begin{array}{c}194 \\
(08-36-09-25)\end{array}$ & 194 & $\mathrm{AmB}+\mathrm{FC}$ \\
\hline \multirow[t]{3}{*}{6} & Female & $+/ 1996$ & CSF & $12 / 06 / 00$ & $\begin{array}{c}0 \\
(08-36-10-56) \\
\end{array}$ & 0 & $\begin{array}{c}\text { AmB+FC } \\
\text { Flu (maintenance) }\end{array}$ \\
\hline & & & CSF & $12 / 10 / 00$ & $\begin{array}{c}123 \\
(08-36-10-52) \\
\end{array}$ & 123 & $\begin{array}{c}\text { AmB } \\
\text { Flu (maintenance) }\end{array}$ \\
\hline & & & CSF & $30 / 10 / 00$ & $\begin{array}{c}19 \\
(08-36-10-53)\end{array}$ & 142 & $A m B+F C$ \\
\hline \multirow[t]{4}{*}{7} & Male & - & CSF & 09/01/01 & $\begin{array}{c}0 \\
(08-36-09-26) \\
\end{array}$ & 0 & $\begin{array}{c}\text { AmB+ltr } \\
\text { Flu (maintenance) }\end{array}$ \\
\hline & & & CSF & $17 / 04 / 01$ & $\begin{array}{c}99 \\
(08-36-09-30) \\
\end{array}$ & 99 & $\begin{array}{c}\text { AmB+Flu } \\
\text { Flu (maintenance) }\end{array}$ \\
\hline & & & CSF & 07/06/01 & $\begin{array}{c}52 \\
(08-36-09-78)\end{array}$ & 151 & Flu+Itr \\
\hline & & & Semen & 19/06/01 & $\begin{array}{c}13 \\
(08-36-09-42)\end{array}$ & 164 & Liposomal AmB \\
\hline
\end{tabular}

performed with maximal heating and cooling settings $\left(5^{\circ}\right.$ $\mathrm{C} / \mathrm{s})$. ii) Detection and sizing of amplification products with subsequent assignment of repeat numbers: the fragments obtained were combined with the ET550-R size standard (GE Healthcare, Diegem, Belgium) and analyzed on a MegaBACE 500 automated DNA platform (GE Healthcare), according to the instructions of the manufacturer. Electropherograms were analyzed using Fragment Profiler 1.2 software (GE Healthcare). Identical isolates were those that possessed alleles with the same number of repeat units in all nine loci. Consistent with the previous separation of genotypes into microsatellites complexes (MC's), isolates with genotypes that differed in up to two loci were considered to be genetically related [12]. Genotypes differing in more than two loci were considered to be unrelated. The study was approved by the Scientific Council and Ethics Committee of the Instituto Pedro Kouri, Havana, Cuba.

\section{Results}

The majority of strains were obtained from HIV positive patients, except those recovered from patient 7 for whom no underlying disease could be demonstrated (Table 1). The mean number of isolates/patient was 2.71 (range 2-4 isolates/patients). The mean time between collection of any two isolates was 52.5 days (range 13-123 days). All 
patients received antifungal treatment but only the HIV negative patient (nr. 7) survived. All clinical strains were identified as $C$. neoformans var. grubii serotype A and mating-type $\alpha$.

For the antifungal susceptibility testing, no differences between visual and spectrophotometric readings were observed, and the MICs for the quality control strains were all within the suggested reference ranges (data not shown). Table 2 summarizes the in vitro susceptibilities of the isolates according to the origin of the strains. When all data were considered together, the widest ranges and highest MICs were for fluconazole (0.25 to 8 $\mu \mathrm{g} / \mathrm{mL}$ ) and flucytosine ( 0.5 to $8 \mu \mathrm{g} / \mathrm{mL})$ and the lowest were for isavuconazole, voriconazole, and posaconazole. Amphotericin B, posaconazole and isavuconazole exhibited similar MICs patterns among all the studied isolates. Isolates from patients 6 and 7 exhibited a stepwise increase among serial isolates for some of the drugs. Increased MICs values of at least $4 \log _{2}$ dilutions over the time for fluconazole, itraconazole, voriconazole and isavuconazole were observed in patient 6 . In patient 7 higher MICs were found between initial and last isolate for fluconazole $\left(4 \log _{2}\right)$, itraconazole $\left(6 \log _{2}\right)$ and voriconazole $\left(5 \log _{2}\right)$. Amphotericin B, flucytosine and posaconazole demonstrated maximally only a $1-3 \log _{2}$ difference among serial isolates.
STR patterns of the 19 isolates showed 14 distinct profiles. Three patients (patients 2, 3 and 6) had genotypically identical isolates over the course of time. The serial isolates from patient 6 were genotypically identical but also showed the largest difference in MIC for the triazoles including drugs which have not been used (itraconazole, voriconazole, isavuconazole). The other four patients were probably infected by more than one genotype (Figure 1) although this might be biased because from each positive CSF culture only one colony was archived for future study.

\section{Discussion}

No previous studies of the antifungal susceptibility and genetic diversity of sequential isolates of $C$. neoformans obtained from individual patients have been done in Cuba. Here we studied 19 serial clinical strains of $C$. neoformans from 7 patients with recurrent cryptococcal meningitis during the pre-HAART period by analyzing their antifungal susceptibility and molecular profiles.

Our results on the in vitro activities of the main antifungal drugs are similar to those published previously [15-17]. Amphotericin B has long successfully been used to treat various yeasts and mould infections. In this series there was only one $\log _{2}$ dilution difference between the sequential isolates with a highest observed MIC of

Table 2 Minimum inhibitory concentration of all C. neoformans var. grubii isolates for seven antifungal drugs

\begin{tabular}{|c|c|c|c|c|c|c|c|c|}
\hline \multirow[t]{2}{*}{ Patient Nr. } & \multirow{2}{*}{$\begin{array}{c}\text { Strain } \\
\text { Nr. }\end{array}$} & \multicolumn{7}{|c|}{ Minimum Inhibitory Concentration $(\mu \mathrm{g} / \mathrm{mL})$ reading at $72 \mathrm{~h}$} \\
\hline & & $A m B$ & FC & Flu & Itr & Vor & Pos & Isa \\
\hline \multirow[t]{3}{*}{1} & 08-36-09-92 & 0.125 & 8 & 4 & 0.125 & 0.016 & 0.125 & 0.016 \\
\hline & 08-36-09-75 & 0.25 & 2 & 4 & 0.063 & $<0.016$ & 0.063 & $<0.004$ \\
\hline & $08-36-10-01$ & 0.25 & 4 & 4 & 0.25 & 0.125 & 0.125 & $<0.004$ \\
\hline \multirow[t]{3}{*}{2} & 08-36-09-97 & 0.125 & 2 & 1 & 0.031 & 0.063 & 0.125 & $<0.004$ \\
\hline & 08-36-09-70 & 0.25 & 2 & 2 & 0.063 & 0.063 & 0.125 & 0.016 \\
\hline & 08-36-09-91 & 0.125 & 1 & 1 & 0.031 & $<0.016$ & 0.063 & 0.008 \\
\hline \multirow[t]{2}{*}{3} & 08-36-09-71 & 0.25 & 2 & 2 & 0.063 & 0.063 & 0.016 & 0.016 \\
\hline & 08-36-09-72 & 0.125 & 8 & 2 & 0.125 & 0.125 & 0.031 & $<0.004$ \\
\hline \multirow[t]{2}{*}{4} & 08-36-09-82 & 0.25 & 2 & 2 & 0.031 & 0.031 & 0.031 & 0.008 \\
\hline & 08-36-09-89 & 0.25 & 1 & 4 & 0.031 & 0.125 & 0.063 & 0.008 \\
\hline \multirow[t]{2}{*}{5} & 08-36-09-24 & 0.25 & 2 & 1 & $<0.016$ & $<0.016$ & 0.016 & 0.004 \\
\hline & 08-36-09-25 & 0.25 & 1 & 0.25 & 0.031 & $<0.016$ & 0.016 & $<0.004$ \\
\hline \multirow[t]{3}{*}{6} & 08-36-10-56 & 0.125 & 0.5 & 0.25 & $<0.016$ & $<0.016$ & 0.063 & $<0.004$ \\
\hline & $08-36-10-52$ & 0.125 & 0.5 & 4 & 0.125 & 0.125 & 0.016 & 0.031 \\
\hline & 08-36-10-53 & 0.25 & 1 & 8 & 0.125 & 0.25 & 0.016 & 0.063 \\
\hline \multirow[t]{4}{*}{7} & 08-36-09-26 & 0.25 & 0.5 & 0.5 & $<0.016$ & $<0.016$ & 0.031 & 0.016 \\
\hline & 08-36-09-30 & 0.25 & 0.5 & 0.5 & 0.031 & 0.031 & 0.016 & 0.004 \\
\hline & 08-36-09-78 & 0.125 & 1 & 1 & 0.031 & 0.063 & 0.016 & $<0.004$ \\
\hline & $08-36-09-42$ & 0.25 & 4 & 8 & 0.5 & 0.25 & 0.031 & $<0.004$ \\
\hline
\end{tabular}

Abreviations: AmB: amphotericin B, FC; flucytosine, Flu; fluconazole, Itr; itraconazole, Vor; voriconazole, Pos; posaconazole, Isa; isavuconazole. 


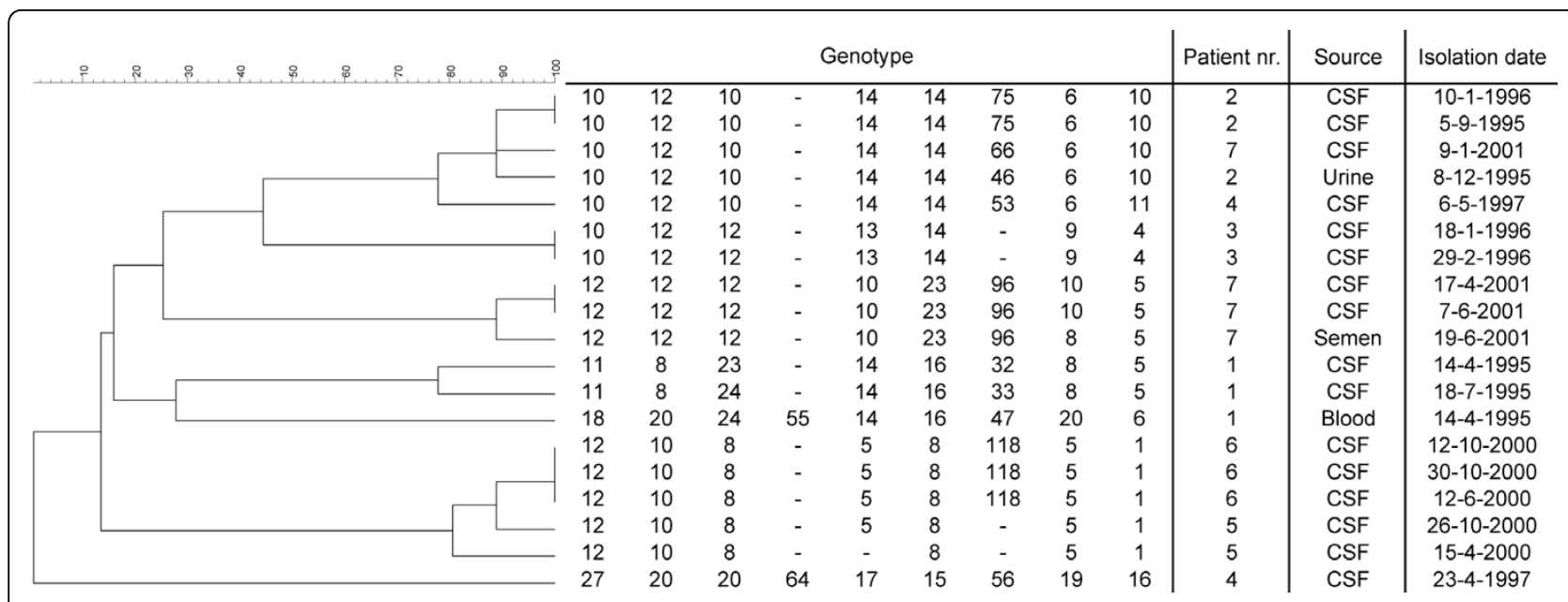

Figure 1 Details of the $19 \mathrm{C}$. neoformans isolates from 7 patients and relationship between the obtained genotypes. The numbers below the genotype correspond to the number of repetitions observed in markers CNA2a, CNA2b, CNA2c, CNA3a, CNA3b, CNA3c, CNA4a, CNA4b and CNA4c, respectively. A hyphen indicates that no result was obtained. The dendrogram is based on a categorical analysis using UPGMA clustering. The scale bar indicates the percentage similarity.

$0.25 \mu \mathrm{g} / \mathrm{mL}$ way below the suggested breakpoint for resistance of MIC $\geq 2 \mu \mathrm{g} / \mathrm{mL}$, which was found to be associated with therapeutic failure [18]. All flucytosine MICs were $<16 \mu \mathrm{g} / \mathrm{mL}$ which are regarded as susceptible $[7,14]$. Among the azoles, fluconazole showed the lowest in vitro activity. In fact, previous reports have already demonstrated the low activity of this drug against C. neoformans isolates, even though it has proven to be more active in vivo [19]. According to these authors, the good therapeutic results obtained are largely attributable to its high concentrations in cerebrospinal fluid. Although no resistance has been found in the present collection of isolates ( $\mathrm{MIC}<16 \mu \mathrm{g} / \mathrm{mL}$ ) [20], a stepwise increase of 4 and 5 dilutions was found in 2 patients suggesting development of reduced levels of antifungal susceptibility [7]. In one patient (nr. 6) the sequential isolates were genotypically identical. Of interest is the finding that the increase of fluconazole MICs over time in patients 6 and 7 parallels data with itraconazole, voriconazole and isavuconazole but not with posaconazole. These observations support previous work that suggests the development of cross-resistance of fluconazole with other triazoles [20]. Isavuconazole is an experimental broad-spectrum antifungal triazole active against clinically relevant yeasts and moulds [21]. Our results are in agreement with previously published studies which demonstrated a high in vitro activity of this drug for C. neoformans $[17,22]$. It has been demonstrated that there are no trends towards higher MICs for strains isolated from patients who failed to respond to a given therapy compared to isolates from patients who did not [23]. On the other hand, patient 4 was infected with two different genotypes with similar susceptibility profiles. Because the short time in between each isolation it is suggestive that this was not a recurrent infection, it is possible that the patient was infected simultaneously with both strains. Patients 2 and 5 had three and two isolates respectively with similar susceptibility patterns. In the first case only the CSF isolates were genotypically similar. This might imply that this patient was also infected simultaneously with more than one strain however there might be a bias because mixed infections in one sample of morphologically similar cryptococci might have been missed. In the second case, isolates differed in one marker and were thus considered to be genetically related. These observations suggest microevolution of $C$. neoformans during human infection. This process may allow the fungal population to change and escape eradication by the immune system, and thus cause chronic infections as suggested by Jain $e t$ al. [24]. Patient 1 had two baseline isolates, from blood and CSF, that had similar susceptibility but were genotypically different. Since both genotypes were isolated simultaneously this could mean that the patient was infected with both strains at time of first sampling. As has been stated before we might have missed mixed infection at baseline because not all (morphologically) similar colonies were studied. After more than three months of fluconazole maintenance therapy, the patient was re-admitted because signs and symptoms of relapse. The CSF isolate obtained at that time had higher MIC values for voriconazole and a different genotype compared with the previous isolates. These findings suggest two possibilities: i) the patient was re-infected with a new strain during the maintenance therapy or ii) the initial strains underwent genetic microevolution. 
Cerebrospinal fluid from patient 7 remained microscopically (Indian ink) and culture positive during more than 5 months, despite antifungal therapy. Only the second and third isolate showed the same genotype which was different from the first and the fourth isolate. This could be explained by simultaneous infection with more than one strain or by re-infection with a new strain during treatment which developed genetic changes over time. This is corroborated by the increased MICs values for fluconazole, itraconazole and voriconazole of the last isolate.

Other authors have studied the molecular relationship of $C$. neoformans isolates obtained from the same episode of infection or during a recurrent infection with several different techniques [10,11,24-26]. Although the obtained results are variable, most authors suggest that persistence or recurrence of the infection is caused by relapse rather than re-infection and/or microevolution of the original isolate [20,25-28]. Multiple strain infection was rarely considered until a recent study reported a high frequency of mixed infections in $20 \%$ of patients with cryptococcal disease and speculated that multiple strains could be exogenously acquired from the environment, either simultaneous or sequentially [29]. A bias was entered in our study because only one colony was selected for archiving from each sampling point (because all growing colonies were morphologically similar). Morphological similar colonies might have different genotypic backgrounds as has been shown recently [29].

\section{Conclusions}

STR typing as presented in this study has not been largely used for Cryptococcus molecular characterization. This new typing technique allowed the observation of high genetic variability among the studied clinical isolates keeping in mind the previous mentioned limitation of this study and we confirm the observation of withinhost strain diversity [29]. Recurrence of infection in the majority of these patients were not associated with drug resistance but probably by co-infection with different strains or strains genetically modified during the long maintenance therapy.

\footnotetext{
Acknowledgements

This study was supported by a research and travel grant from the International Society for Human and Animal Mycology to MTIZ. We thank M Perurena-Lancha for her assistance. The funding agency had no role in study design, data collection and analysis, decision to publish, or preparation of the manuscript.

\section{Author details}

'Department of Bacteriology and Mycology, Instituto Pedro Kourí, Havana, Cuba. ${ }^{2}$ CBS-Fungal Biodiversity Centre, Utrecht, The Netherlands. ${ }^{3}$ Department of Medical Microbiology and Infectious Diseases, Canisius Wilhelmina Hospital, Nijmegen, The Netherlands.
}

\section{Authors' contributions}

MTIZ and FH carried out the susceptibility testing and molecular typing, and drafted the manuscript. MTIZ GFMM and CMFA participated in the design of the study, contributed materials and cared for the clinical management of the patients. TB CHWK and JFM conceived of the study, and participated in its design and coordination and helped to draft the manuscript. All authors read and approved the final manuscript.

\section{Competing interests}

JFM received grants form Astellas, Basilea, Merck, and Schering-Plough. He has been a consultant to Basilea, Merck and Schering-Plough and received speakers fees from Gilead, Janssen Pharmaceutica, Merck, Pfizer, and Schering-Plough. CHWK received a grant from Pfizer. All other authors: no potential conflicts of interest.

Received: 20 May 2010 Accepted: 4 October 2010

Published: 4 October 2010

References

1. Bicanic T, Harrison TS: Cryptococcal meningitis. Br Med Bull 2005, 72:99-118.

2. Park BJ, Wannemuehler KA, Marston BJ, Govender N, Pappas PG, Chiller TM: Estimation of the current global burden of cryptococcal meningitis among persons living with HIV/AIDS. AIDS 2009, 23:525-30.

3. Spitzer ED, Spitzer SG, Freundlich LF, Casadevall A: Persistence of initial infection in recurrent Cryptococcus neoformans meningitis. Lancet 1993, 341:595-596

4. Casadevall A, Spitzer ED, Webb D, Rinaldi MG: Susceptibilities of serial Cryptococcus neoformans isolates from patients with recurrent cryptococcal meningitis to amphotericin B and fluconazole. Antimicrob Agents Chemother 1993, 37:1383-1386.

5. Pfaller M, Zhang J, Messer S, Tumberland M, Mbidde E, Jessup C, Ghannoum M: Molecular epidemiology and antifungal susceptibility of Cryptococcus neoformans isolates from Ugandan AIDS patients. Diagn Microbiol Infect Dis 1998, 32:191-199.

6. Dromer F, Bernede-Bauduin C, Guillemot D, Lortholary O, French Cryptococcosis Study Group: Major role for amphotericin B-flucytosine combination in severe cryptococcosis. PLoS One 2008, 3(8):e2870.

7. Perfect JR, Dismukes WE, Dromer F, Goldman DL, Graybill JR, Hamill RJ, Harrison TS, Larsen RA, Lortholary O, Nguyen MH, Pappas PG, Powderly WG, Singh N, Sobel JD, Sorrell TC: Clinical practice guidelines for the management of cryptococcal disease: 2010 update by the Infectious Diseases Society of America. Clin Infect Dis 2010, 50:291-322.

8. Nussbaum JC, Jackson A, Namarika D, Phulusa J, Kenala J, Kanyemba C, Jarvis JN, Jaffar S, Hosseinipour MC, Kamwendo D, van der Horst CM, Harrison TS: Combination flucytosine and high-dose fluconazole compared with fluconazole monotherapy for the treatment of cryptococcal meningitis: a randomized trial in Malawi. Clin Infect Dis 2010, 50:338-344.

9. Fusco-Almeida AM, Teruyuki-Matsumoto M, Baeza LC, Bellan de Oliveira R, Pizzirani-Kleiner AA, de Souza Carvalho-Melhem M, Mendes-Giannini MJS: Molecular typing and antifungal susceptibility of clinical sequential isolates of Cryptococcus neoformans from Sao Paulo State, Brazil. FEMS Yeast Res 2007, 7:152-164.

10. Haynes KA, Sullivan DJ, Coleman DC, Clarke JC, Emilianus R, Atkinson C, Cann KJ: Involvement of multiple Cryptococcus neoformans strains in a single episode of cryptococcosis and reinfection with novel strains in recurrent infection demonstrated by random amplification of polymorphic DNA and DNA fingerprinting. J Clin Microbiol 1995, 33:99-102.

11. Sullivan D, Haynes K, Moran G, Shanley D, Coleman D: Persistence, replacement, and microevolution of Cryptococcus neoformans strains in recurrent meningitis in AIDS patients. J Clin Microbiol 1996, 34:1739-1744.

12. Illnait-Zaragozi MT, Martínez-Machín GF, Fernández-Andreu CM, Boekhout T, Meis JF, Klaassen CH: Microsatellite typing of clinical and environmental Cryptococcus neoformans var. grubii isolates from Cuba shows multiple genetic lineages. PLoS One 2010, 9;5(2):e9124.

13. Clinical and Laboratory Standards Institute: Reference method for broth dilution antifungal susceptibility testing of yeasts. Approved standard. M27-A3. Clinical and Laboratory Standards Institute, Wayne, PA , 3 2008. 
14. Barreto de Oliveira MT, Boekhout T, Theelen B, Hagen F, Baroni FA, Lazera MS, Lengeler KB, Heitman J, Rivera IN, Paula CR: Cryptococcus neoformans shows a remarkable genotypic diversity in Brazil. J Clin Microbiol 2004, 42:1356-1359.

15. Pfaller MA, Messer SA, Boyken L, Hollis RJ, Rice C, Tendolkar S, Diekema DJ: In vitro activities of voriconazole, posaconazole, and fluconazole against 4,169 clinical isolates of Candida spp. and Cryptococcus neoformans collected during 2001 and 2002 in the ARTEMIS global antifungal surveillance program. Diagn Microbiol Infect Dis 2004, 48:201-205.

16. Messer SA, Moet GJ, Kirby J, Jones RN: Activity of contemporary antifungal agents, including the novel echinocandin anidulafungin, tested against Candida spp., Cryptococcus spp., and Aspergillus spp.: Report from the SENTRY Antimicrobial Surveillance Program (2006 to 2007). J Clin Microbiol 2009, 47:1942-1946.

17. Illnait-Zaragozi MT, Martínez FG, Curfs-Breuker I, Fernández CM, Boekhout T, Meis JF: In vitro activity of the new azole isavuconazole (BAL4815) compared with six other antifungal agents against 162 Cryptococcus neoformans isolates from Cuba. Antimicrob Agents Chemother 2008 , 52:1580-1582.

18. Lozano-Chiu M, Paetznick VL, Ghannoum MA, Rex JH: Detection of resistance to amphotericin B among Cryptococcus neoformans clinical isolates: performances of three different media assessed by using E-test and National Committee for Clinical Laboratory Standards M27-A methodologies. J Clin Microbiol 1998, 36:2817-2822.

19. Aller Al, Martin-Mazuelos E, Lozano F, Gomez-Mateos J, Steele-Moore L, Holloway WJ, Gutierrez MJ, Recio FJ, Espinel-Ingroff A: Correlation of fluconazole MICs with clinical outcome in cryptococcal infection. Antimicrob Agents Chemother 2000, 44:1544-1548.

20. Mondon P, Petter R, Amalfitano G, Luzzati R, Concia E, Polacheck I, KwonChung KJ: Heteroresistance to fluconazole and voriconazole in Cryptococcus neoformans. Antimicrob Agents Chemother 1999, 43:856-861.

21. Guinea J, Bouza E: Isavuconazole: a new and promising antifungal triazole for the treatment of invasive fungal infections. Future Microbiol 2008, 3:603-615.

22. Thompson GR III, Wiederhold NP, Fothergill AW, Vallor AC, Wickes BL, Patterson TF: Antifungal susceptibilities among different serotypes of Cryptococcus gattii and Cryptococcus neoformans. Antimicrob Agents Chemother 2009, 53:309-311.

23. Dannaoui E, Abdul M, Arpin M, Nguyen AM, Piens MA, Favel A, Lortholary O, Dromer F: Results obtained with various antifungal susceptibility testing methods do not predict early clinical outcome in patients with cryptococcosis. Antimicrob Agents Chemother 2006, 50:2464-2470.

24. Jain N, Wickes BL, Keller SM, Fu J, Casadevall A, Jain P, Ragan MA, Banerjee U, Fries BC: Molecular epidemiology of clinical Cryptococcus neoformans strains from India. J Clin Microbiol 2005, 43:5733-5742.

25. Litvintseva A P, Kestenbaum L, Vilgalys R, Mitchell TG: Comparative analysis of environmental and clinical populations of Cryptococcus neoformans. J Clin Microbiol 2005, 43:556-564.

26. Igreja RP, Dos Santos-Lazera M, Wanke B, Gutierrez-Galhardo MC, Kidd SE, Meyer W: Molecular epidemiology of Cryptococcus neoformans isolates from AIDS patients of the Brazilian City, Rio de Janeiro. Med Mycol 2004, 42:229-238.

27. Fries BC, Casadevall A: Serial isolates of Cryptococcus neoformans from patients with AIDS differ in virulence for mice. J Infect Dis 1998, 178:1761-1766.

28. Friese G, Discher T, Füssle R, Schmalreck A, Lohmeyer J: Development of azole resistance during fluconazole maintenance therapy for AIDSassociated cryptococcal disease. AIDS 2001, 15:2344-2345.

29. Desnos-Ollivier M, Patel S, Spaulding AR, Charlier C, Garcia-Hermoso D, Nielsen K, Dromer F: Mixed infections and in vivo evolution in the human fungal pathogen Cryptococcus neoformans. mBio 1(1), pii: e0009110.

\section{Pre-publication history}

The pre-publication history for this paper can be accessed here: http://www.biomedcentral.com/1471-2334/10/289/prepub

\section{doi:10.1186/1471-2334-10-289}

Cite this article as: Illnait-Zaragozí et al: Microsatellite typing and susceptibilities of serial Cryptococcus neoformans isolates from Cuban patients with recurrent cryptococcal meningitis. BMC Infectious Diseases 2010 10:289.

\section{Submit your next manuscript to BioMed Central and take full advantage of:}

- Convenient online submission

- Thorough peer review

- No space constraints or color figure charges

- Immediate publication on acceptance

- Inclusion in PubMed, CAS, Scopus and Google Scholar

- Research which is freely available for redistribution

Submit your manuscript at www.biomedcentral.com/submit
Ciomed Central 